Pesq. Vet. Bras. 29(7):589-597, julho 2009

\title{
Doenças do sistema nervoso central de equídeos no semi-árido ${ }^{1}$
}

\author{
Luciano A. Pimentel ${ }^{2}$, Diego M. de Oliveira², Glauco J.N. Galiza², Rafael O. do \\ Rego², Antônio Flávio M. Dantas ${ }^{2}$ e Franklin Riet-Correa ${ }^{*}$
}

\begin{abstract}
Pimentel L.A., Oliveira D.M., Galiza G.J.N., Rego R.O., Dantas A.F.M. \& Riet-Correa F. 2009. [Diseases of the central nervous system in equidae in the Brazilian semiarid.] Doenças do sistema nervoso central de equídeos no semi-árido. Pesquisa Veterinária Brasileira 29(7):589-597. Hospital Veterinário, Universidade Federal de Campina Grande, Campus de Patos, Patos, PB 58700-000, Brazil. E-mail: franklin.riet@pq.cnpq.br

Diseases of the central nervous system (CNS) in equidae are important in these species, and their knowledge in the different Brazilian regions is necessary to determine efficient control and preventive measures. This paper reports epidemiologic aspects, clinical signs and pathology of diseases of the CNS in equidae diagnosed by the Veterinary Pathology Laboratory at the Federal University of Campina Grande in the city of Patos, state of Paraíba, northeastern Brazil, during 2002-2008. During the period, 159 cases or outbreaks of those diseases were studied, 49 (30.8\%) affecting the CNS. Hepatic encephalopathy caused by Crotalaria retusa poisoning, with 14 cases $(28.5 \%)$, was the main disease observed. Tetanus was diagnosed in $13(26.5 \%)$ cases and rabies in 11 $(22.4 \%)$. In seven $(14.2 \%)$ cases the death or euthanasia was due to traumatic lesions of the CNS. Also were diagnosed 1 case of leucoencephalomalacia, 1 case of encephalitis by equine herpesvirus-1, 1 case of intracarotid artery injection, 1 outbreak of Eastern equine encephalitis, 1 of Turbina cordata poisoning, and 1 of a tremogenic disease of unknown cause. In 5 cases the diagnosis was inconclusive. This paper indicates the importance of diagnostic veterinary laboratories, in the different Brazilian regions, for the knowledge of livestock diseases.
\end{abstract}

INDEX TERMS: Eastern equine encephalitis, equine herpesvirus-1, hepatic encephalopathy, intracarotid artery injection, equine leucoencephalomalacia, rabies, tetanus.

RESUMO.- As doenças do sistema nervoso central (SNC) de equídeos representam uma parcela importante das enfermidades diagnosticadas nestas espécies. O estudo destas e de outras enfermidades nas diferentes regiões do país é necessária para estabelecer formas eficientes de controle e profilaxia. O presente trabalho teve como objetivo descrever as características clínicas, epidemiológicas e patológicas das doenças do SNC de equídeos

\footnotetext{
${ }^{1}$ Recebido em 9 de março de 2009

Aceito para publicação em 27 de março de 2009.

Parte da dissertação do primeiro autor no Programa de Mestrado em Medicina Veterinária de Ruminantes e Equídeos, Universidade Federal de Campina Grande (UFCG), Patos, PB, Brasil.

${ }^{2}$ Centro de Saúde e Tecnologia Rural (CSTR), UFCG, Campus de Patos, 58700-000 Patos, Paraíba. *Autor para correspondência: franklin.riet@pq.cnpq.br
}

diagnosticadas no Laboratório de Patologia da Universidade Federal de Campina Grande, em Patos, Paraíba, que ocorreram entre janeiro de 2007 e dezembro de 2008. No período estudado, 159 casos ou surtos de doenças de equídeos foram diagnosticados. Destes, $49(30,8 \%)$ afetaram o SNC. A encefalopatia hepática na intoxicação por Crotalaria retusa foi a principal enfermidade com $14 \mathrm{ca}-$ sos $(28,5 \%)$, seguida por tétano com $13(26,5 \%)$ casos e raiva com $11(22,, 4 \%)$ casos. Sete $(14,2 \%)$ casos foram de traumatismos afetando o SNC. Foram, também, diagnosticados 1 caso de leucoencefalomalacia, 1 de encefalite por herpesvírus eqüino-1, 1 de injeção acidental na artéria carótida, 1 surto de encefalomielite viral equina tipo leste, 1 surto de intoxicação por Turbina cordata e 1 surto de doença tremogênica de causa desconhecida. Cinco casos tiveram diagnóstico inconclusivo. Este trabalho comprova a importância do funcionamento de laboratóri- 
os de diagnóstico, nas diferentes regiões do país, para o conhecimento das doenças do rebanho e para a vigilância epidemiológica das mesmas.

TERMOS DE INDEXAÇÃO: Encefalomielite equina leste, encefalopatia hepática, herpesvírus eqüino-1, injeção acidental na artéria carótida, leucoencefalomalacia, raiva, tétano.

\section{INTRODUÇÃO}

As doenças do sistema nervoso central (SNC) de equídeos representam uma parcela importante das enfermidades diagnosticadas nestas espécies. O estudo destas e de outras enfermidades nas diferentes regiões do país é necessária para estabelecer formas eficientes de controle $e$ profilaxia. Com esse objetivo, o Hospital Veterinário (HV) do Centro de Saúde e Tecnologia Rural (CSTR) da Universidade Federal de Campina Grande (UFCG) em Patos, Paraíba, têm realizado diagnóstico das doenças nos animais domésticos na região semi-árida do nordeste do Brasil, principalmente no estado da Paraíba, mas também em alguns municípios dos estados de Pernambuco, Rio Grande do Norte e Ceará. Para uma correta vigilância epidemiológica das doenças do SNC dos equídeos é importante o diagnóstico conclusivo das encefalomielites que afetam ou podem afetar essas espécies no semi-árido, assim como o seu diagnóstico diferencial. É importante também conhecer os fatores que limitam a equideocultura na região devido ao uso destes animais em atividades esportivas e para o trabalho. O presente estudo tem como objetivo descrever as características clínicas, epidemiológicas e patológicas das doenças do SNC de equídeos diagnosticadas no Laboratório de $\mathrm{Pa}$ tologia Animal (LPA) do HV/CSTR/UFCG, que ocorreram entre janeiro de 2002 e dezembro de 2008.

\section{MATERIAL E MÉTODOS}

O trabalho foi desenvolvido no Laboratório de Patologia Animal da Universidade Federal de Campina Grande, Centro de Saúde e Tecnologia Rural, Campus de Patos, Paraíba. Foram revisadas todas as fichas de necropsia e fichas da clínica de grandes animais (CGA) referentes aos equídeos com diagnóstico de doenças do sistema nervoso no período de janeiro de 2002 a dezembro de 2008 . No período de março de 2007 a dezembro de 2008 foram acompanhados todos os casos de equídeos que ingressaram ao HV e/ou foram necropsiados e de matérias encaminhados ao LPA por veterinários da área de influência.

Os dados coletados foram referentes à história, epidemiologia, sinais clínicos, achados de necropsias e alterações histológicas. Nas fichas da CGA foram coletados dados da história clínica, exame clínico, protocolo de tratamento e evolução dos casos. Do material revisado no LAP foram separadas as lâminas histológicas para observação e caracterização das alterações encontradas e, quando necessário, foram confeccionadas novas lâminas a partir dos blocos de parafina ou do material acondicionado em formol, resgatando também registros fotográficos. Dos casos que não foi possível revisão ou reconfecção de lâminas foi feita a transcrição dos achados contidos nas fichas do arquivo.
Dos casos acompanhados foi coletado SNC (encéfalo e medula cervical, torácica e lombar) e de fragmentos de órgãos das cavidades torácica e abdominal, que foram fixados em formol a $10 \%$ tamponado. Depois de fixados foram feitos cortes de várias porções do SNC incluindo córtex frontal, parietal, temporal e occipital, núcleos da base, tálamo, colículos rostral e caudal, ponte e pedúnculos cerebelares, óbex, cerebelo, medula cervical, torácica e lombar e gânglio e nervo trigêmeo. Depois de clivados todos os fragmentos foram encaminhados para diafanização e embebição em parafina, sendo posterior-

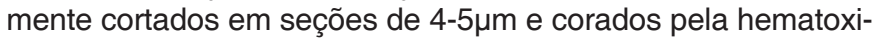
lina e eosina (HE).

Para o diagnóstico da raiva metade do encéfalo e fragmentos das diferentes porções da medula, foram refrigerados e/ou congelados e encaminhados ao laboratório de virologia da UFCG para realização das técnicas de imunoflorescência, e inoculação em camundongos. Em 12 casos de encefalomielites de origem infecciosa, com diagnóstico positivo ou não para raiva, foi realizada a técnica de imuno-histoquímica (IHQ) para raiva. Em um caso, material refrigerado foi enviado ao Instituto Pasteur, da Secretaria de Saúde de São Paulo, para diagnóstico de encefalomielite viral equina por reação de transcrição reversa seguida de reação em cadeia pela polimerase, RT-PCR e NESTED-PCR. A imuno-histoquímica foi realizada a partir de cortes histológicos convencionais em lâminas silanizadas, posteriormente seguiu-se protocolo de rotina desta técnica por meio de bloqueio da peroxidase endógena, recuperação antigênica, bloqueio de reações inespecíficas, aplicação de anticorpo primário (policlonal de raiva produzido em cabras (FIT - Chemicon 5199) na diluição de 1:1000, aplicação do conjugado LSAB (anticorpo secundário, complexo enzimático estreptavidina-biotina-peroxidase), aplicação do cromógeno $\mathrm{DAB}$ (3, 3' diamino-benzidinetetrahydrochloride) e contra corado por meio da Hematoxilina de Harris. Esta técnica foi realizada no Laboratório de Patologia Veterinária da Universidade Federal de Santa Maria, RS. Em 9 dos 12 casos submetidos à técnica de imuno-histoquímica foram confeccionadas lâminas de fragmentos do córtex, tálamo, cerebelo e medula de cada um. Nos outros 3 casos, somente 2 fragmentos do SNC foram testados.

\section{RESULTADOS}

No período estudado foram registrados no LPA/HV 159 casos isolados ou surtos envolvendo equídeos, e as causas da morte ou razões para eutanásia foram subdivididas de acordo com o sistema afetado, constatando-se 49 $(30,8 \%)$ casos de enfermidades do SNC, $29(18,2 \%)$ que afetaram o sistema locomotor, $27(16,9 \%)$ o sistema digestivo, $11(6,9 \%)$ o sistema tegumentar, $7(4,4 \%)$ o sistema respiratório, $5(3,1 \%)$ o sistema cardiovascular e 9 $(5,6 \%)$ afetando diversos sistemas. Em $22(13,8 \%)$ casos o diagnóstico foi inconclusivo. Nas afecções do SNC a espécie mais afetada foi a equina.

\section{Encefalopatia hepática por Crotalaria retusa}

Os únicos equídeos afetados por esta intoxicação foram os equinos, 14 casos foram diagnosticados no referido período. Seis do total de casos descritos ocorreram entre os anos de 2002 e 2003 e já foram descritos por Nobre et al. (2004), por tanto os dados aqui apresentados 
Quadro 1 Dados epidemiológicos referentes aos casos de intoxicação por Crotalaria retusa diagnosticados no LPA/HV de maio de 2003 a dezembro de 2008

\begin{tabular}{|c|c|c|c|c|c|c|c|}
\hline $\begin{array}{l}\text { Caso } \\
\text { no. }\end{array}$ & $\begin{array}{l}\text { Evolução } \\
\text { da doença }\end{array}$ & Idade & Sexo & Raça & Mês/Ano & $\begin{array}{l}\text { Presença da } \\
\text { planta na } \\
\text { pastagem }\end{array}$ & Município \\
\hline 1 & 20 dias & 4 anos & M & $\begin{array}{l}\text { Quarto } \\
\text { de Milha }\end{array}$ & Maio/2003 & $\operatorname{sim}$ & Santa Luzia, PB \\
\hline 2 & 30 dias & 8 anos & $\mathrm{F}$ & SRD & Março/2005 & $\mathrm{n} / \mathrm{i}^{\mathrm{b}}$ & Patos, PB \\
\hline 3 & 22 dias & 6 anos & M & SRD & Julho/2005 & Sim & $\begin{array}{l}\text { São José de } \\
\text { Espinharas, PB }\end{array}$ \\
\hline 4 & 24 horas & 12 anos & M & SRD & Julho/2006 & $\mathrm{n} / \mathrm{i}$ & Patos, PB \\
\hline 5 & 27 dias & 12 anos & $\mathrm{F}$ & SRD & julho/2006 & $\mathrm{n} / \mathrm{i}$ & Patos, PB \\
\hline 6 & 19 dias & 2 anos & M & SRD & Janeiro/2007 & Sim & Patos, PB \\
\hline 7 & 48 horas & 4 anos & $\mathrm{F}$ & $\mathrm{n} / \mathrm{i}$ & Julho/2007 & Sim & Brejo Santo, CE \\
\hline 8 & 15 dias & 4 anos & M & SRD & Dezembro/2007 & $\mathrm{n} / \mathrm{i}$ & Patos, PB \\
\hline
\end{tabular}

a Os casos diagnosticados antes de maio de 2003 foram relatados por Nobre et al. (2004).

${ }^{\mathrm{b}} \mathrm{n} / \mathrm{i}=$ dado não informado.

serão referentes a 8 novos casos que estão representados no Quadro 1, com os respectivos dados epidemiológicos. Sete casos ocorreram em municípios da Paraíba e um no estado do Ceará. Em algumas propriedades onde ocorreram os casos, havia histórico de que tinha ocorrido a morte de outros equinos apresentando o mesmo quadro clínico, e foi relatada a presença de Crotalaria retusa na pastagem. A idade dos animais variou entre 2 e 12 anos, mas a enfermidade afetou a mesma quantidade de jovens de até 3 anos e de adultos.

Os sinais clínicos comumente observados nestes casos foram emagrecimento progressivo, anorexia, apatia, depressão acentuada, pressão da cabeça contra objetos, ataxia, debilidade, andar em círculos, quedas e decúbito. Sinais de lesões nos núcleos dos nervos cranianos foram observados em alguns casos (Casos 1, 2, 7 e 8) e se caracterizaram por ptose labial e diminuição dos reflexos pupilar, da deglutição e do tônus da língua. Sinais respiratórios como dispnéia, taquipnéia e corrimento nasal foram vistos em metade dos casos (Casos 1, 4, 6 e 7). A evolução clínica da doença variou de 1 a 30 dias, mas em 6 casos a evolução foi igual ou maior que 15 dias.

As alterações macroscópicas observadas foram, principalmente, no fígado que apresentava superfície capsular irregular, com acentuação do padrão lobular, caracterizada por áreas avermelhadas entremeadas por áreas páli- das. Ao corte, os fígados estavam com consistência aumentada e essas áreas irregulares, avermelhadas e pálidas se aprofundavam por todo o parênquima. Nos Casos 1, 2, 5 e 8, os pulmões estavam não colapsados, brilhantes, ao corte fluía sangue e ainda havia presença de líquido espumoso na traquéia e brônquios.

Microscopicamente, em todos os casos foi observada fibrose periportal difusa, às vezes formando pontes, variando de discreta a acentuada. Vacuolização fina do citoplasma de hepatócitos, necrose e hemorragia centrolobular a mediozonal e necrose individual de hepatócitos também foram observados. Verificou-se também megalocitose, proliferação de células epiteliais de ductos e estase biliar. Em 4 casos (Casos 2, 5, 7 e 8) havia fibrose hepática na superfície capsular com projeções para o parênquima. No encéfalo verificaram-se astrócitos tumefeitos com cromatina dispersa, muitas vezes formando grupos de dois ou mais astrócitos, denominados de astrócitos Alzheimer tipo II (AT2), localizados, principalmente, no córtex cerebral e núcleos da base. Nos Casos 4, 7 e 8 havia ainda moderada gliose e hemorragias perivasculares. A distribuição das lesões histológicas do fígado e a presença de AT2 estão devidamente representadas no Quadro 2. Nos pulmões observou-se principalmente congestão, edema e hemorragias, em 5 casos (Ca$\operatorname{sos} 2,4,6,7$, e 8).

Quadro 2. Dados histológicos referentes aos diagnósticos de encefalopatia hepática por Crotalaria retusa realizados_pelo LPA/HV maio de 2003 a dezembro de 2008

\begin{tabular}{|c|c|c|c|c|c|c|c|c|}
\hline \multirow{2}{*}{$\begin{array}{c}\text { Caso } \\
\text { no. }\end{array}$} & \multicolumn{2}{|c|}{ Fibrose } & \multirow{2}{*}{$\begin{array}{l}\text { Vacuolização } \\
\text { do citoplasma }\end{array}$} & \multirow{2}{*}{$\begin{array}{l}\text { Necrose e } \\
\text { hemorragia }\end{array}$} & \multirow{2}{*}{$\begin{array}{c}\text { Proliferação } \\
\text { celular de } \\
\text { ductos biliares }\end{array}$} & \multirow{2}{*}{$\begin{array}{l}\text { Megalo- } \\
\text { citose }\end{array}$} & \multirow{2}{*}{$\begin{array}{c}\text { Estase } \\
\text { biliar }\end{array}$} & \multirow{2}{*}{$\begin{array}{c}\text { Astrócitos } \\
\text { de Alzheimer } \\
\text { T-2 }\end{array}$} \\
\hline & Cápsula & $\begin{array}{l}\text { Periportal } \\
\text { e/ou difusa }\end{array}$ & & & & & & \\
\hline 1 & - & +++ & + & +++ & ++ & - & - & $n / a^{c}$ \\
\hline 2 & $t^{a}$ & ++ & - & + & - & + & - & ++ \\
\hline 3 & - & + & ++ & - & +++ & - & - & + \\
\hline 4 & - & +++ & - & + & ++ & ++ & ++ & ++ \\
\hline 5 & ++ & +++ & + & +++ & +++ & ++ & - & + \\
\hline 6 & - & +++ & - & ++ & - & ++ & ++ & + \\
\hline 7 & +++ & +++ & ++ & ++ & ++ & ++ & - & ++ \\
\hline 8 & ++ & +++ & + & +++ & ++ & + & - & +++ \\
\hline
\end{tabular}

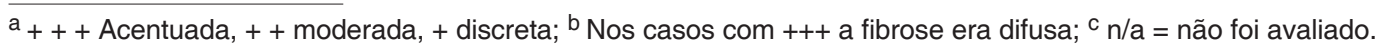


Quadro 3. Dados clínicos e epidemiológicos dos casos de tétano diagnosticados no LPA/HV de janeiro de 2002 a dezembro de 2008

\begin{tabular}{|c|c|c|c|c|c|c|c|}
\hline $\begin{array}{c}\text { Caso } \\
\text { no. }\end{array}$ & Espécie & Idade & Sexo & $\begin{array}{l}\text { Observação } \\
\text { de ferida } \\
\text { prévia }\end{array}$ & Mês/Ano & $\begin{array}{l}\text { Evolução } \\
\text { da doença }\end{array}$ & Município \\
\hline 1 & Equina & 10 anos & $M$ & $\mathrm{n} / \mathrm{i}$ & Novembro/2002 & 5 dias & São José do Egito, PE \\
\hline 2 & Equina & 23 dias & $\mathrm{F}$ & $n / i$ & Novembro/2003 & 5 dias & Patos, PB \\
\hline 3 & Asinina & 7 anos & M & $\operatorname{sim}$ & Junho/2005 & 5 dias & Patos, PB \\
\hline 4 & Equina & $\mathrm{n} / \mathrm{i}^{\mathrm{a}}$ & M & $\operatorname{sim}$ & Outubro/2005 & $\mathrm{n} / \mathrm{i}$ & Santa Luzia, PB \\
\hline 5 & Muar & 14 anos & M & $\operatorname{sim}$ & Março/2006 & 7 dias & Caatingueira, PB \\
\hline 6 & Asinina & 10 anos & $M$ & $\operatorname{sim}$ & Junho/2007 & 5 dias & Patos, PB \\
\hline 7 & Equina & $\mathrm{n} / \mathrm{i}$ & M & $\operatorname{sim}$ & Julho/2007 & 9 dias & São José do Egito, PE \\
\hline 8 & Equina & adulto & M & $\operatorname{sim}$ & Agosto/2007 & 6 dias & Patos, PB \\
\hline 9 & Asinina & 2,5anos & $M$ & $\operatorname{sim}$ & Dezembro/2007 & 7 dias & Patos, PB \\
\hline 10 & Equina & 4 anos & M & $\operatorname{sim}$ & Agosto/2008 & 3 dias & Mãe D’água, PB \\
\hline 11 & Muar & 8anos & $\mathrm{F}$ & $\operatorname{sim}$ & Agosto/2008 & 3 dias & Patos, PB \\
\hline 12 & Equina & 4anos & $M$ & $\mathrm{n} / \mathrm{i}$ & Agosto/2008 & 3 dias & Patos, PB \\
\hline 13 & Equina & 8 anos & $\mathrm{M}$ & $\operatorname{sim}$ & Outubro/2008 & 5 dias & Guaraci, PE \\
\hline
\end{tabular}

a $n / i=$ dado não informado.

\section{Tétano}

No LPA foram registrados 13 casos de tétano no período estudado, sendo 8 em equinos, 3 em asininos e $2 \mathrm{em}$ muares. Em 10 destes casos havia história prévia de feridas ou lesões que caracterizaram a porta de entrada de Clostridium tetani, as exceções foram os Casos 1, 2 e 12. Nos Casos 4 e 10 havia sido realizada castração dos animais há 20 dias e 9 dias, respectivamente, antes do aparecimento dos sinais clínicos. No Caso 9, o histórico era de ferida perfurante por prego há 20 dias e no Caso 13 o ferimento foi causado por arame. Nos demais casos não foram mencionadas a natureza dos ferimentos. O tempo de evolução da enfermidade entre o aparecimento dos sinais clínicos e a morte do animal variou entre 3 e 9 dias, sendo que em 5 casos (Casos 1, 2, 3, 6 e 13) o período foi de 5 dias. Os dados epidemiológicos sobre esta enfermidade encontram-se no Quadro 3. Os sinais clínicos observados em algum momento da evolução clínica comuns a todos os casos foram incapacidade de se alimentar, rigidez muscular generalizada, prolapso de terceira pálpebra, cauda em bandeira, posição de cavalete e evolução para decúbito. Na necropsia não foram observados achados significativos, além dos ferimentos já descritos na clínica.
Nas fichas da CGA, no mesmo período estudado, foram levantados dados de todos os casos de tétano, e destes, 8 casos (Quadro 4) tiveram tratamento eficaz e receberam alta. Obteve-se êxito semelhante no tratamento das espécies asininas e equinas, sendo 4 casos cada uma. A sintomatologia foi semelhante à observada nos casos em que os animais morreram. $O$ tratamento dos que morreram e dos que recuperaram foi o mesmo, e consistiu em limpeza e desinfecção das feridas, condições ambientais de silêncio e tranqüilidade, soroterapia específica do tétano, antibioticoterapia com penicilinas e uso de tranqüilizantes (acepromazina). Em todos os casos de tétano registrados no HV o tratamento foi iniciado no mesmo dia em que deram entrada. O tempo decorrido entre a observação dos sinais clínicos e o inicio do tratamento na clínica variou de 2 a 15 dias, mas em 5 casos o período foi maior que 5 dias que somados ao tempo de permanência na CGA resultou num período total de 15 a 27 dias de evolução clínica.

\section{Raiva}

Esta doença viral foi a terceira em número de casos e/ ou surtos no presente estudo. Foram diagnosticados 11 casos, sendo $10 \mathrm{em}$ equinos e apenas $1 \mathrm{em}$ asinino. Ani-

Quadro 4. Dados referentes aos casos clínicos de tétano com eficácia no tratamento realizado pela CGA/HV de janeiro de 2002 a dezembro de 2008

\begin{tabular}{cccccccc}
\hline Caso & Espécie & Mês/Ano & Idade & Sexo & Raça & $\begin{array}{c}\text { Período decorrido } \begin{array}{c}\text { Tempo de } \\
\text { entre aparecimento } \\
\text { de sinais e início } \\
\text { do tratamento }\end{array} \\
\text { permanência } \\
\text { no HV }\end{array}$ \\
\hline A & Asinina & Fevereiro/2002 & 2 anos & M & SRD & 10 dias & 8 dias \\
B & Equina & Junho/2003 & 6 anos & M & Quarto de Milha & 9 dias & 12 dias \\
C & Asinina & Março/2005 & n/ia & M & SRD & n/i & 20 dias \\
D & Asinina & Abril/2005 & 10 anos & M & SRD & 3 dias & 14 dias \\
E & Asinina & Junho/2005 & 7 anos & M & SRD & 5 dias & 10 dias \\
F & Equina & Dezembro/2006 & 12 anos & M & Quarto de Milha & 2 dias & 10 dias \\
G & Equina & Abril/2007 & 3 anos & $M$ & SRD & 7 dias & 15 dias \\
H & Equina & Novembro/2007 & 7 anos & M & Quarto de Milha & 15 dias & 12 dias
\end{tabular}

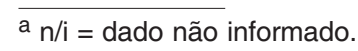


Quadro 5. Dados epidemiológicos dos casos de raiva registrados no LPA/HV de 2002 a 2008 e resultados da técnica de imuno-histoquímica

\begin{tabular}{|c|c|c|c|c|c|c|}
\hline $\begin{array}{c}\text { Caso } \\
\text { no. }\end{array}$ & Espécie & Idade & Sexo & Mês/Ano & Município & $\begin{array}{c}\text { Resultado } \\
\text { da IHQ }\end{array}$ \\
\hline 1 & Equina & 1,7anos & M & Junho/2002 & Patos, PB & Positivo \\
\hline $2^{*}$ & Equina & 5 anos & $\mathrm{M}$ & Junho/2002 & São J. do Bofim, PB & Negativo \\
\hline $3^{*}$ & Equina & 4 meses & $\mathrm{M}$ & Julho/2002 & Patos, PB & Positivo \\
\hline $4^{*}$ & Equina & 1ano & $M$ & Julho/2002 & Patos, PB & Positivo \\
\hline $5^{*}$ & Equina & 5 anos & $M$ & Janeiro/2003 & Patos, PB & Positivo \\
\hline 6 & Equina & 1,2anos & $M$ & Maio/2003 & Santa Luzia, PB & Positivo \\
\hline $7^{\star}$ & Equina & 1 ano & $\mathrm{F}$ & Junho/2004 & Taípu, RN & Positivo \\
\hline 8 & Equina & 3 anos & $\mathrm{F}$ & Maio/2005 & Pombal, PB & Positivo \\
\hline 9 & Equina & $\mathrm{n} / \mathrm{i}^{\mathrm{a}}$ & $\mathrm{n} / \mathrm{i}$ & Março/2007 & Nova Cruz, RN & Positivo \\
\hline 10 & Asinina & Jovem & $\mathrm{F}$ & Março/2007 & Patos, PB & Positivo \\
\hline 11 & Equina & 1,5anos & $\mathrm{M}$ & Setembro/2007 & Patos, PB & Positivo \\
\hline
\end{tabular}

${ }^{*}$ Casos anteriormente descritos por Lima 2005; ${ }^{a}$ n/i = dado não informado.

mais jovens e adultos foram afetados, mas em 8 casos a idade foi de menos de 3 anos. Os meses de ocorrência em 9 casos foram entre março e julho, e apenas um caso (Caso 5) em janeiro e outro (Caso 11) em setembro. Também 9 casos foram provenientes de municípios do semiárido do estado da Paraíba e apenas dois, de municípios do Rio Grande do Norte. Cincos casos aqui citados já foram descritos em outro estudo de raiva por Lima et al. (2005). Em todos os casos desta enfermidade foi realizada a técnica de IHQ e, portanto, os dados referentes a esta técnica incluem todos os casos diagnosticados no período, incluindo os casos descritos por Lima et al. (2005). Os dados clínicos e histopatológicos referem-se, apenas, aos 6 novos casos. Os dados epidemiológicos e o resultado da imuno-histoquímica estão descritos no Quadro 5. Apenas o Caso 2, que tinha sido diagnosticado anteriormente por imunoflorescência e inoculação de camundongos foi negativo para esta técnica. O Caso 9 foi proveniente de um surto onde 7 equinos apresentavam sinais nervosos e morreram após curso clínico de 24-48 horas, todos vacinados para raiva e encefalomielites virais. $O$ Caso 8 era proveniente de um surto onde morreram 5 equinos com sinais de debilidade nos membros posteriores e crises convulsivas. O animal que deu entrada no HV encontrava-se em decúbito lateral. Na mesma propri- edade, 3 cães foram eutanasiados por apresentar sinais neurológicos, mas nenhum material dos cães foi encaminhado ao laboratório de diagnóstico.

Os sinais clínicos comumente observados foram diminuição ou ausência de sensibilidade ao teste do panículo, do ânus e da cauda e do reflexo flexor dos membros e graus variáveis de paresia e paralisia principalmente dos membros pélvicos, seguidas de decúbito. Na necropsia, os achados macroscópicos foram inespecíficos da doença como escoriações na pele e hematomas subcutâneos provavelmente de traumas sofridos durante a evolução clínica, ampola retal repleta e bexiga cheia.

$\mathrm{Na}$ histopatologia das secções coradas pelo hematoxilina-eosina $(\mathrm{HE})$ a presença de infiltrado inflamatório mononuclear com predominância de linfócitos foi observada nos espaços de Virchow-Robin, principalmente em fragmentos da medula dos seis casos, menos comumente foram vistos também graus variáveis de gliose, hemorragias, esferóides axonais e necrose neuronal, na substância cinzenta medular. As mesmas lesões em menor grau estavam presentes também no córtex, tálamo, núcleos basais, tronco encefálico e cerebelo nos Casos 8, 9 e 10. Nos outros três casos (Casos 1, 6 e 11) foram observadas apenas lesões medulares. Somente em um dos 6 casos descritos neste trabalho (Caso 10) foram obser-

Quadro 6. Dados referentes aos diagnósticos de traumatismos realizados pelo LPA/HV no período de janeiro de 2002 a dezembro de 2008

\begin{tabular}{|c|c|c|c|c|c|c|}
\hline $\begin{array}{l}\text { Caso } \\
\text { no. }\end{array}$ & Espécie & Idade & Sexo & Mês/Ano & $\begin{array}{l}\text { Motivo } \\
\text { (causa) }\end{array}$ & $\begin{array}{c}\text { Vértebras onde } \\
\text { se localizava } \\
\text { a lesão }\end{array}$ \\
\hline 1 & Equina & 8 anos & M & Dezembro/2002 & $\mathrm{n} / \mathrm{i}^{\mathrm{a}}$ & $n / i$ \\
\hline 2 & Equina & 5 anos & M & Setembro/2003 & Acidente manejo & $14^{\mathrm{a}}$ e $15^{\mathrm{a}}$ torácicas \\
\hline 3 & Asinina & adulto & M & Abril/2004 & Acidente manejo & $5^{\mathrm{a}}$ cervical \\
\hline 4 & Muar & 8 anos & M & Novembro/2005 & $\mathrm{n} / \mathrm{i}$ & $6^{\underline{a}}$ e $7^{\mathrm{a}}$ torácicas \\
\hline 5 & Equina & 12 anos & M & Agosto/2006 & Briga & $12^{\mathrm{a}}$ torácica \\
\hline 6 & Asinina & adulto & M & Março/2007 & $\begin{array}{c}\text { Atropelamento } \\
\text { automotivo }\end{array}$ & $15^{\mathrm{a}}, 16^{\underline{a}}$ e $17^{\mathrm{a}}$ torácicas \\
\hline 7 & Asinina & adulto & $\mathrm{F}$ & Setembro/2007 & $\begin{array}{l}\text { Atropelamento } \\
\text { automotivo }\end{array}$ & $6^{a}$ e $7^{a}$ torácicas \\
\hline
\end{tabular}

$\overline{a_{n} / \mathrm{i}=\text { dado não informado. }}$. 
vados corpúsculos de inclusão viral (corpúsculos de Negri) no pericário dos neurônios de Purkinje do cerebelo.

$\mathrm{Na} \mathrm{IHQ}$ dos segmentos submetidos à técnica houve uma maior imuno-marcação no tálamo (7/8), seguidos de córtex (5/8), no cerebelo e medula (4/8).

\section{Traumatismos}

Sete casos de traumatismo vertebral foram diagnosticados no período, sendo $3 \mathrm{em}$ asininos, $3 \mathrm{em}$ equinos e 1 em muar. Todos os animais eram adultos, seis machos e uma fêmea, e eram oriundos do estado da Paraíba. No histórico informado pelos proprietários a origem das lesões foi atropelamento nos Casos 6 e 7, acidentes de manejo nos Casos 2 e 3, briga com outro eqüídeo no Caso 5 , e nos Casos 1 e 4 não foi informada a causa, apenas os animais foram encontrados em decúbito. Traumatismo vertebral foi a principal lesão em todos os casos, e ao exame físico os animais apresentavam-se em decúbito lateral, debatendo-se, com paresia ou paralisia dos membros. No Caso 1, o animal apresentava também sensibilidade dolorosa ao toque na região lombar dorsal, relaxamento do ânus e paralisia da cauda. No Caso 4 havia paralisia espástica dos membros. Em alguns casos iniciou-se tratamento, mas em todos eles os animais foram encaminhados para eutanásia devido ao mau prognóstico. Nas necropsias, múltiplas escoriações na pele, hemorragias e laceração dos tecidos moles ao redor da coluna vertebral foram predominantemente observadas, assim como fratura vertebral parcial ou completa, com conseqüente compressão ou rompimento da medula. A localização da lesão vertebral de cada caso esta descrita no Quadro 6. Nos Casos 3 e 7 foram também observadas fraturas do osso frontal, e nos Casos 5 e 6 houve luxação da articulação femoro-tibio-patelar e fratura de costelas, respectivamente.

\section{Leucoencefalomalacia}

Em abril de 2002 um equino, macho, da raça Quarto de Milha com 1 ano e 3 meses de idade, procedente do município de Santa Luzia, na Paraíba, deu entrada na $\mathrm{CGA} / \mathrm{HV}$, com histórico de ser alimentado com uma ração composta de farelo de milho e trigo. Ao exame físico o animal apresentou apatia, andar cambaleante, cegueira, andar em círculos e pressão da cabeça contra objetos, evoluindo para depressão profunda. Posteriormente apresentou decúbito lateral, movimentos de pedalagem e coma, seguida de morte. A evolução clinica de foi de aproximadamente 72 horas. Na necropsia após abertura do crânio o hemisfério cerebral direito encontrava-se com consistência amolecida e, ao corte, foram observadas cavitações com bordas irregulares e material liquefeito no interior. Foram observadas, também, áreas de coloração amarelo acinzentada na substância branca subcortical no córtex parietal de ambos os hemisférios e múltiplos focos avermelhados com distribuição irregular e congestão das meninges. Na histologia foi observada congestão cerebral difusa, com necrose da substância branca, ca- racterizada por cavitações de tamanhos variados, múltiplos focos aleatórios de hemorragia, astrócitos reativos com citoplasma eosinofílico condensado e núcleo picnótico (clasmatodendrócitos) e edema caracterizado por áreas homogêneas eosinofílicas. No exame do alimento foi detectada fumomisina $B_{1}(47 \mu \mathrm{g} / \mathrm{g})$ e nas culturas foi isolado Fusarium proliferatum.

\section{Injeção acidental na artéria carótida}

Em junho de 2007 deu entrada no HV um equino macho, mestiço, com 10 anos de idade, proveniente do município de São Bento, Rio Grande do Norte. O Animal tinha histórico que apresentava há cinco meses aumento de volume no prepúcio, diagnosticado posteriormente como carcinoma de células escamosas metastático. No exame clínico, para a exposição do pênis, optou-se pela sedação do animal, com cloridrato de xilazina a 10\%, via intravenosa, o que resultou na aplicação acidental deste fármaco na artéria carótida. Os sinais clínicos imediatamente após a aplicação foram decúbito lateral, convulsões, nistagmo, taquicardia e sudorese intensa. No mesmo dia o animal ficou em estação e alimentou-se normalmente, mas ao ser movimentado, apresentava hiperexcitabilidade e episódios de quedas. No dia seguinte verificou-se apatia, debilidade, ataxia, anorexia, nistagmo, ausência do reflexo palpebral e pupilar, hipoalgesia facial, flacidez da língua, desvio lateral da cabeça, torneios e quedas, além de movimentos involuntários dos lábios e ptose labial. O quadro clínico se manteve estável durante nove dias, mas o animal desenvolveu múltiplas escaras de decúbito e relutava em caminhar. Após 10 dias, o cavalo ficou em decúbito lateral e morreu em 48 horas.

$\mathrm{Na}$ necropsia foram observadas apenas alterações relacionadas ao carcinoma epidermóide do pênis que apresentava metástases para linfonodos inguinais. Histologicamente no encéfalo observou-se material eosinofílico homogêneo e amorfo no espaço de Virchow-Robin, com alguns vasos apresentando tumefação das células endoteliais, principalmente no tálamo, córtex e cerebelo. Havia também congestão e hemorragia adjacente, além de múltiplos trombos em vasos das leptomeninges e hialinização da parede de vasos. Observaram-se também áreas multifocais de microcavitações ou vacúolos (status espogiosus) com alguns astrócitos reativos (gemistócitos) no neurópilo do córtex e tálamo.

\section{Mielite por herpesvírus equino-1}

No mês de março de 2002 deu entrada no HV um eqüino macho de três anos de idade, proveniente do município de Patos. Clinicamente apresentava, há dois dias, incoordenação dos membros posteriores e quedas. Quando foi examinado, dois dias após o início dos sinais, apresentava-se em decúbito lateral. Quando forçado a ficar em estação afirmava os membros torácicos, mas não conseguia afirmar os membros pélvicos. Apresentava gemidos, diminuição da sensibilidade na região sacra, reflexo anal ausente e reflexos digitais dos membros pél- 
vicos diminuídos. Notava-se diminuição do tônus muscular, paralisia de cauda, incontinência urinária e relaxamento do ânus. Permaneceu em decúbito e morreu durante a noite. Na necropsia foram observadas áreas de coloração cinza escura na medula lombar. As lesões histológicas estavam localizadas preferentemente na medula lombar, onde se observava, tanto na substância branca quanto na cinzenta, vasculite severa com degeneração das paredes do vaso e acúmulo perivascular de linfócitos, plasmócitos e células mononucleares indiferenciadas. Essas lesões vasculares tinham um padrão característico estendendo-se, radialmente, desde as meninges para a substância branca. Lesões inflamatórias semelhantes foram observadas nas meninges. No neurópilo havia também acúmulos multifocais de linfócitos, macrófagos, plasmócitos e células mononucleares indiferenciadas. $\mathrm{Na}$ substância branca havia extensas áreas de malacia localizadas, principalmente, nos funículos ventrais. Nestas áreas observaram-se astrócitos reativos com citoplasma eosinofílico. Tanto na substância branca quanto na cinzenta observavam-se, ocasionalmente, esferóides axonais. Lesões semelhantes, mas de muito menor intensidade, foram observadas tanto na medula torácica, quanto na cervical. O diagnóstico histológico foi confirmado por imuno-histoquímica.

\section{Encefalomielite viral equina tipo leste (EEE)}

No mês de abril de 2008, no município de Parnamerim, Pernambuco, morreram cerca de 40 equinos com sinais nervosos, com curso clínico de 3-5 dias. Posteriormente, a doença ocorreu no município de Exú, Pernambuco, onde morreram cerca de 20 animais entre os meses de maio e setembro. Das propriedades envolvidas nos surtos morreram de um a cinco animais cada uma. A grande maioria das mortes ocorreu no mês de junho. Vale ressaltar que estes cavalos eram utilizados para prática de esporte (vaquejada) e viajaram por outros estados vizinhos como Ceará e Piauí, e alguns deles estavam vacinados contra encefalomielite equina.

Em um caso ocorrido no município de Exú, um equino macho, adulto, apresentou andar a esmo e cambaleante, cegueira, salivação, ranger de dentes, pressão da cabeça contra objetos, quedas, movimentos de pedalagem e decúbito seguido de morte em 3 dias. Na necropsia não foram observadas lesões macroscópicas significativas. $\mathrm{O}$ estudo histológico do SNC revelou encefalite difusa afetando principalmente a substância cinzenta, com meningite e coroidite. Havia também vasculite com infiltração de células linfocitárias, macrófagos e neutrófilos. Observam-se áreas de malacia, degeneração neuronal, neuronofagia, presença de esferóides axonais, gliose, infiltrado de neutrófilos no neurópilo, edemas e hemorragias. As lesões eram mais acentuadas no cérebro, mas foram observadas também, em menor gravidade, no tronco encefálico. O diagnóstico de encefalomielite viral equina tipo leste foi realizado por Nested-PCR em material enviado ao Instituto Pasteur, em São Paulo. Outros dados re- ferentes ao diagnóstico e epidemiologia deste surto serão publicados separadamente (Silva et al. 2009, dados não publicados).

\section{Outros diagnósticos e diagnósticos inconclusivos}

Um surto de intoxicação por Turbina cordata ocorreu no ano de 2006 no município de Juazeiro na Bahia afetando 2 equinos, machos, sem raça definida, adultos, criados em pasto nativo. Havia cerca de 1 ano e 9 meses os animais apresentavam ataxia, tremores de intenção e tremores dos lábios que se intensificavam quando eram movimentados. Havia também hipermetria, estação com os membros abertos, relutância em caminhar quando puxados pelo cabresto, com saltos e quedas e emagrecimento progressivo. Não foram realizadas necropsias.

Em um surto foi diagnosticada doença tremogênica de causa desconhecida. Na época a enfermidade ocorreu também em outras 7 fazendas dos municípios de Boa Vista, Cabaceiras e Campina Grande em equídeos que apresentaram tremores, andar cambaleante e quedas quando excitados. Os surtos ocorreram durante a seca em piquetes com muito pasto seco, principalmente Digitaria spp. e Chloris spp. Os animais se recuperavam em aproximadamente uma semana após serem retirados dos pastos. A descrição detalhada destes surtos e respectivos estudos experimentais com diversas plantas serão publicados separadamente (Clarice Macêdo 2009, dados não publicados).

Em 5 casos de equídeos com sinais neurológicos não foram observadas alterações macroscópicas ou histológicas que permitissem o diagnóstico.

\section{DISCUSSÃO}

Os resultados do presente trabalho demonstram que as enfermidades do SNC de equídeos representam uma parcela importante nas diferentes patologias que acometem estas espécies no semi-árido. A intoxicação por Crotalaria retusa descrita anteriormente (Nobre et al. 2004) o tétano e a raiva são as doenças mais freqüentes. Em relação ao tétano os veterinários não têm dificuldades de diagnóstico, mas no caso da intoxicação por $C$. retusa o diagnóstico diferencial deve incluir, principalmente, as encefalites virais (raiva e encefalomielite viral equina). No caso da raiva o diagnóstico diferencial pode ser feito pelo curso clínico geralmente mais prolongado na intoxicação por $C$. retusa, assim como pelos sinais ou alterações da bioquímica sanguínea sugestivas de insuficiência hepática (Nobre et al. 2004). Em qualquer uma das duas doenças o diagnóstico laboratorial é simples e definitivo.

O tétano é a segunda doença mais freqüentemente diagnosticada como causa de morte e a principal doença se considerarmos os animais que se recuperaram. Embora o prognóstico seja desfavorável, alguns animais se recuperam com tratamento adequado. No período estudado, 21 casos de tétano foram diagnosticados entre a CGA e o LPA/HV, sendo que 8 casos (38\%) se recupera- 
ram com tratamento. Em estudos da doença realizados por Reichmann et al. (2008) em equinos, a taxa de recuperação foi $29,5 \%$ de 61 casos tratados e o tempo entre o início dos sintomas e o tratamento quando maior que 5 dias foi um forte indicador de bom prognóstico. Os indicadores de mau prognóstico foram a observação de incapacidade de se alimentar e a apresentação em decúbito dos animais ao exame físico ou a rápida evolução para este sinal clínico. No presente estudo, em 5 casos, o período entre inicio dos sinais clínicos e o tratamento foi igual ou maior que 5 dias nos animais que se recuperaram e em todos os casos que foram encaminhados pela CGA/HV para eutanásia, os animais encontravam-se em decúbito lateral e com dificuldade respiratória. A vacinação sistemática de todos os equinos contra esta doença é a meIhor forma de evitar as mortes e o gasto com tratamento (Raposo 2007).

A raiva é a doença viral dos equinos de maior importância no semi-árido. No presente estudo houve uma maior prevalência entre os meses de março e julho, final do período chuvoso e inicio do período seco. De 32 surtos de raiva em ruminantes e equídeos, 28 ocorreram em período similar, entre os meses de março e agosto (Lima et al. 2005), o que sugere a vacinação dos equídeos no início do período das chuvas, em janeiro e fevereiro. Animais jovens foram mais afetados do que os adultos, provavelmente por que por não terem sido vacinados ou terem sido vacinados somente uma vez, sem revacinação aos 20-30 dias, apresentam menor imunidade. O principal vetor desta enfermidade na região pareceria ser, como no resto do País, Desmodus rotundos, mas vírus rábico tem sido isolado, também de raposas (Gomes 2004). A raiva em equídeos é indistinguível clinicamente de outras encefalites e o apoio laboratorial é indispensável para o diagnóstico. A presença de corpúsculos de Negri é um achado histológico altamente significativo, mas foi observado em somente 3 de 11 animais, um dos casos descritos neste trabalho e 2 dos casos descritos por Lima et al. (2005), caracterizando a necessidade de que técnicas como a imunoflorescência, inoculação de camundongos ou imuno-histoquímica, devem ser empregadas. Estudos de diagnóstico da raiva em equinos e bovinos demonstram que os corpúsculos de Negri são mais comuns na espécie bovina com cerca de $80 \%$ dos casos enquanto que para os equinos foi de $36 \%$ (Peixoto et al. 2000). A imuno-histoquímica realizada no presente estudo foi negativa em apenas um caso, mais de $90 \%$ de positividade. Esta técnica é rápida e de grande precisão, o que possibilita o diagnóstico definitivo a partir de materiais já fixados em formol (Barros et al. 2006) e permite estudos retrospectivos (Pedroso 2008). De todos os fragmentos testados as secções do tálamo mostraram o maior índice de marcação, o que sugere que deve ser a região preferencialmente testada.

A ocorrência de numerosos casos de traumatismo da coluna vertebral como causa de morte em cavalos chama a atenção para a necessidade de adotar técnicas mais adequadas para o manejo destes animais evitando riscos desnecessários para a integridade dos mesmos, seja em atividades de trabalho ou de esporte e lazer.

A leucoencefalomalacia equina (LEME) comumente observada na região Sul e sudeste (Riet-Correa et al. 1998, Riet-Correa \& Méndez 2007), foi recentemente diagnosticada também em Pernambuco (Câmara et al. 2008) e no Pará (Riet-Correa et al. 2007), demonstrando que ocorre em todo o País. No Sul e Sudeste a doença ocorre principalmente no inverno, enquanto que no Nordeste não há uma distribuição sazonal evidente e provavelmente esteja relacionada com a quantidade de ração fornecida e condições de armazenagem do milho (Câmara et al. 2008). O histórico de alimentação com milho ou subprodutos e a realização da correta necropsia para constatar as lesões macroscópicas características são importantes para o diagnóstico desta intoxicação.

Doença nervosa causada por inoculação de medicamentos na carótida é um acidente raro em equinos e que ocorre sobretudo quando se trata de injetar medicamentos na jugular, no terço inferior do pescoço (Gabel \& Koestner 1963). Para evitar este acidente os medicamentos devem ser injetados na porção anterior da jugular, onde a mesma está separada da carótida pelos músculos omoióideo e esternocefálico (Christian et al. 1974). Na parte inferior do pescoço a jugular está muito próximo da carótida existindo o risco de inoculação intracarotídea (Smith 2006).

Dentre as doenças causadas por vírus foi diagnosticado um único caso de encefalomielite por herpesvírus eqüino-1, com lesões histológicas características da doença (Summers et al. 1995). Herpesvírus eqüino-1 pode causar doença respiratória (rinopneumonia), abortos e sinais nervosos em eqüinos. A forma nervosa pode ocorrer após um episódio de rinopneumonia ou abortos, ou isoladamente. No Brasil a forma mais freqüente da doença são os abortos (Weiblen 2007).

$O$ diagnóstico de um surto de encefalite viral equina tipo leste (EEE) chama a atenção para a importância desta arbovirose no semi-árido. Antes de estabelecer o diagnóstico laboratorial no HV/UFCG o diagnóstico clínico presuntivo de encefalomielite viral equina era muito freqüente, principalmente em uma doença conhecida como "roda", por parte dos veterinários de campo, mas nenhum caso da doença tinha sido confirmado como encefalomielite viral equina. Neste surto nos municípios pernambucanos atingidos a doença também era designada como "roda". Uma característica importante para o suspeita da doença é a sua ocorrência epidêmica nas épocas de ocorrência dos vetores mosquitos dos gêneros Culex e Aedes, diferentemente do que ocorre nas outras doenças encontradas neste estudo, que são doenças endêmicas. Embora diversos surtos de EEE em humanos sejam descritos nos Estados Unidos (Del Piero et al. 2001), no Brasil há descrição de apenas um caso (Figueiredo 2007). Estabelecer sistemas de vigilância para encefalomielite viral equina nas diferentes regiões do Bra- 
sil é muito importante, tanto pelo seu caráter zoonótico, quanto pela possibilidade da introdução de novas arboviroses no País, como é o caso da Encefalite do Oeste do Nilo. Esta doença, freqüente em outros continentes, foi diagnosticada em 1999 nos EUA (USDA/APHIS 2003), onde ocasionou a morte de pelos menos 965 pessoas entre os anos de 1999 e 2006 (Kramer et al. 2008). Em 2006 foi diagnosticada na Argentina causando mortes em equinos (Rocha 2006).

Este trabalho comprova a importância do funcionamento de laboratórios de diagnóstico, nas diferentes regiões do país, para o conhecimento das doenças do rebanho e para a vigilância epidemiológica das mesmas.

\section{REFERÊNCIAS}

Barros C.L.S., Driemeier D., Dutra I.S. \& Lemos R.A.A. 2006. Doenças causadas por vírus e príon, p.21-28. In: Ibid. (Eds), Doenças do Sistema Nervoso de Bovinos no Brasil. Coleção Vallée, São Paulo. 207p.

Câmara A.C.L., Afonso J.A.B., Riet-Correa F., Dantas A.F.M., Mendonça C.L., Costa N.A., Dantas A.C., Neto H.A.C., Campos A.G.S.S. \& Souza M.I. 2008. Leucoencefalomalácia em equídeos no estado de Pernambuco. Ciênc. Anim. Bras. 9(2):470-479.

Christian R.G., Mills J.H.L. \& Kramer L.L.1974. Accidental intracarotid artery injection of promazine in the horse. Can. Vet. J. 15:29-33.

Del Piero F., Wilkins P.A., Dubovi E.J., Biolatti B. \& Cantile C. 2001. Clinical, pathologic, immunohistochemical, and virologic findings of eastern equine encephalomyelitis in two horses. Vet. Pathol. 38:451456.

Figueiredo L.T.M. 2007. Arboviroses emergentes no Brasil. Revta Soc. Bras. Med. Trop. 40(2):224-229.

Gabel A.A. \& Koestner A. 1963. The effects of intracarotid artery injection of drugs in domestic animals. J. Am. Vet. Med. Assoc. 142:1397-1403.

Gomes A.A.B. 2004. Epidemiologia da raiva: caracterização de vírus isolados de animais domésticos e silvestres do semi-árido paraibano da região de Patos, Nordeste do Brasil. Tese de Doutorado, USP, São Paulo. 107p.

Heinemann M.B., Souza M.C.C., Cortez A., Ferreira F., Homem V.S.F., Ferreira-Neto J.S., Soares R.M., Cunha E.M.S. \& Richtzenhain L.J. 2006. Soroprevalência da encefalomielite equina do leste e do oeste no município de Uruará, PA, Brasil. Braz. J. Vet. Res. Anim. Sci. 43(Supl.):137-139.

Kramer L.D., Styer L.M. \& Ebel G.D. 2008. A global perspective on the epidemiology of West Nile Virus. Annu. Rev. Entomol. 53:61-81.

Lima E.F., Riet-Correa F., Castro R.S., Gomes A.A.B. \& Lima F.S. 2005.
Sinais clínicos, distribuição das lesões no sistema nervoso e epidemiologia da raiva em herbívoros na região Nordeste do Brasil. Pesq. Vet. Bras. 25(4):250-264.

Nobre V.M.T., Riet-Correa F., Barbosa Filho J.M., Dantas A.F.M., Tabosa I.M. \& Vasconcelos J.S. 2004. Intoxicação por Crotalaria retusa (Fabaceae) em eqüídeos no semi-árido da Paraíba. Pesq. Vet. Bras. 24(3):132-143.

Pedroso P.M.C. 2008. Diagnóstico histológico e imuno-histoquímica de raiva em herbívoros. Dissertação de Mestrado, Faculdade de Veterinária, Universidade Federal do Rio Grande do Sul, Porto Alegre. 70p.

Peixoto Z.M.P., Cunha E.M.S., Sacramento D.R.V., Conceição M., Souza A.M., da Silva L.H.Q., Germano P.L., Kroeff S.S. \& Kotait I. 2000. Rabies laboratory diagnosis: Peculiar features of samples from equine origin. Braz. J. Microbiol. 31(1):72-75.

Raposo J.B. 2007. Tétano, p.425-431. In: Riet-Correa F., Schild A.L., Lemos R.A.A. \& Borges J.R. (Eds), Doenças de Ruminantes e Eqüinos. Vol.1. $3^{\text {a }}$ ed. Pallotti, Santa Maria. $722 p$.

Reichmann P., Lisboa J. \& Araujo R. 2008. Tetanus in equids: A review of 76 cases. J. Eq. Vet. Sci. 28(9):518-523.

Riet-Correa G., Duarte M.D., Cerqueira V.D. \& Riet-Correa F. 2007. Leucoencephalomalacia in mules in northern Brazil, p.256-262. In: Panter K.E., Wierenga T.L. \& Pfister J.A. (Eds), Poisonous Plants: Global research and solutions. CAB Wallingford, Oxon, UK.

Riet-Correa F., Meireles M., Barros C. \& Gava A. 1998. Equine leukoencephalomalacia in Brazil, p.479-482. In: Garland T. \& Barr C.A. (Eds), Toxic Plants and other Natural Toxicants. CAB International, Wallingford, UK.

Riet-Correa F. \& Méndez M.C. 2007. Intoxicações por plantas e micotoxinas, p.99-221. In: Riet-Correa F., Schild A.L., Lemos R.A.A. \& Borges J.R. (Eds), Doenças de Ruminantes e Eqüídeos. Vol.2. $3^{\underline{a}}$ ed. Pallotti, Santa Maria. 694p.

Rocha J. 2006. Diagnósticos da América S/A (DASA). Disponível em $<$ www.diagnosticos- daamerica.com.br> Acesso em 25.5.2007.

Smith B.P. 2006. Doenças do sistema nervoso. Injeção intracarotídea de fármaco, p.940. In: Ibid. (Ed.), Medicina Interna de Grandes Animais. $3^{\text {a }}$ ed. Manole, São Paulo. 1727p.

Summers B.A., Cummings J.F. \& de Lahunta A. 1995. Inflammatory disease of the central nervous system, p.95-188. In: Ibid. (Eds), Veterinary Neuropathology. Mosby-Year Book, St Louis. 527p.

USDA/APHIS 2003. Department of Agriculture's/Animal and Plant Health Inspection Service. Disponível em <http://www.aphis.usda.gov/lpa/ pubs/fsheet_faq_notice/faq_ahwnv.htm> Acesso em 25.5.2007.

Weiblen R. 2007. Infecções por herpesvírus equinos, p.138-146. In: Riet-Correa F., Schild A.L., Lemos R.A.A. \& Borges J.R. (Eds), Doenças de Ruminantes e Eqüinos. Vol.1. 3 ${ }^{\underline{a}}$ ed. Pallotti, Santa Maria. $722 p$. 